assessments (WBPA) or should the obvious conclusion be that there is no correlation between demonstrating competence in clinical practice and performing in an exam (something many may argue has been present all the time)? Should we then do away with the final exam altogether (as run-through training under Modernising Medical Careers may allow in some specialties) or return to the old-fashioned part II clinical exam which some (examiners and trainees alike) may argue was a better test of clinical competence and, more importantly, excellence? These are very important questions that the College and the Postgraduate Medical Education and Training Board need to consider, as one should not lose sight of the ultimate goal (becoming a specialist/consultant) of being in a postgraduate medical training programme in any specialty.

Following Lord Darzi's recent review of the National Health Service (NHS), ${ }^{4}$ it has become ever so important for consultants to be at the forefront of driving quality in the modern-day NHS, something that will be difficult to achieve if we do not produce adequate numbers of quality-trained consultants. This may paradoxically suit many strategic health authorities, primary care trusts and NHS trusts! Many medical managers like me are constantly put under pressure to reduce medical costs (there is anecdotal evidence that consultant posts are not being advertised or retiring consultants are not being replaced throughout the country). As consultants remain relatively expensive units, it would suit the NHS ultimately to have fewer. New Ways of Working ${ }^{5}$ is another tool of reducing consultant workload and perhaps ultimately numbers. Thus, if we continue with the current framework of training and assessment, we may inadvertently be facilitating that process.

1 Menon S, Winston M, Sullivan G. Workplace-based assessment: survey of psychiatric trainees in Wales. Psychiatr Bull 2009; 33: 468-74.

2 Babu KS, Htike MM, Cleak VE. Workplace-based assessments in Wessex: the first 6 months. Psychiatr Bull 2009; 33: 474-8.

3 Oyebode F. Competence or excellence? Invited commentary on Workplace-based assessments in Wessex and Wales. Psychiatr Bull 2009; 33: 478-9.

4 Lord Darzi. High Quality Care for All: NHS Next Stage Review Final Report TSO (The Stationery Office), 2008.

5 Department of Health. New Ways of Working for Psychiatrists: Enhancing Effective, Person-Centred Services through New Ways of Working in Multidisciplinary and Multiagency Contexts. TSO (The Stationery Office), 2005

Sudip Sikdar is Consultant Psychiatrist, Clinical Director, Royal College of Psychiatrists' Examiner, and Regional Advisor Mersey, Merseycare NHS Trust, Liverpool. Email: sudip.sikdar@merseycare.nhs.uk

doi: $10.1192 / p b .34 .2 .72 b$

\section{We all have thought processing difficulties from time to time . . . it's just the way we react that differs}

The underlying issues raised by Kingdon ${ }^{1}$ and King $^{2}$ are those in the foundations of the theory and practice of psychiatry. Interestingly, the views expressed echoed, at least in part, some of my own views expressed in another publication:

'Mental illness is never far away as it is simply one end of normality. In other words, we all have thought processing difficulties (TPD) from time to time. Depression is the best example of a thought processing difficulty. However, difficulty may become a disorder when the normal thought processing mechanisms and adaptations fail. A basic mental breakdown, without complicated diagnostic categories, takes place. The manner of the breakdown is unique to the individual sufferer whose internal life is surely more than the standardised criteria set in the scriptures (ICD-10 and DSM- IV)! ${ }^{3}$

The definition of stress adopted by the UK Health and Safety Executive recognised it as relating to pressure and demands: 'the adverse reaction people have to excessive pressures or other types of demand placed on them at work. ${ }^{4}$ The intuitive thinker will immediately see the metaphorical relationship to a hydraulic or fluid-based system. If we accept that the mind is metaphorically fluid, then there will be no real boundaries and categories, making vague but universal concepts valid according to the demands of the specific situation. Thought processing difficulty/disorder is as defensible as 'stress' from a psychopathological perspective as well as in terms of social acceptability and (best of all) accuracy. I have creatively used the acronym TPD (with ' $D$ ' meaning either difficulty or disorder according to the patient's preference) to successfully resolve diagnostic disputes with virtually all my patients who felt stigmatised and erroneously labelled as schizophrenic or as having borderline personality disorder. Most chose ' $D$ ' as representing a difficulty for which they seek help in a collaborative fashion. It is of course less bruising to anyone's ego to accept having a difficulty (or stress) than to accept having a disorder (an implicit indication of socially undesirable or deviant behaviour). Thought processing difficulties/disorder has indeed been my Occam's razor for all psychiatric diagnoses and I recommend it to fellow colleagues. I understand that it will not be specific enough for the 'square thinker' - to use Robert Pirsig's reflection of the views of some African Americans who believed that too much intellectuality and too little soul made a person square. Such a person could not recognise quality, and nothing was real for them unless it was put into boring categories and defined. ${ }^{5}$

1 Kingdon D. Everybody gets stressed . . . it's just the way we react that differs. Psychiatr Bull 2009; 33: 441-2.

2 King M. Reducing the stigma of public health messages. Invited commentary on ... Everybody gets stressed. Psychiatr Bull 2009; 33: 443-4.

3 Metseagharun T. ABC of the Mind: Very Simple Knowledge of the Mind That Promises You Happiness and Fulfilment. AuthorHouse Publishing, 2008

4 Health and Safety Executive. What is Stress? Health and Safety Executive (http://www.hse.gov.uk/stress/furtheradvice/ whatisstress.htm)

5 Pirsig RM. Zen and the Art of Motorcycle Maintenance: An Inquiry into Values. Morrow, 1974.

Temi Metseagharun is a Locum Staff Grade Psychiatrist, Ten Acres Centre, Birmingham and Solihull Mental Health NHS Foundation Trust, Birmingham. Email: drtemi2008@googlemail.com

doi: $10.1192 / p b .34 .2 .73$

\section{Screening tests for dementia}

Only a tiny proportion of the laboratory and radiology tests identify potentially reversible causes of dementia. ${ }^{1}$ However, I would like to sound a note of caution against reducing the use of blood investigations like vitamin $\mathrm{B}_{12}$, folate and thyroid function tests in practice. 
In the largest study in terms of sample size ${ }^{2}$ the authors found that although a potentially reversible cause was found in only $4 \%$ of people with dementia overall, it rose to $19 \%$ when limited to people with a young-onset dementia. They also showed that concomitant conditions that were reversible, like vitamin $B_{12}$ deficiency and thyroid deficiency, were more frequent in patients with mild cognitive deficits than in those meeting the criteria for dementia. Although treatment of these conditions may not always lead to complete resolution of cognitive symptoms, it is important to identify any concomitant conditions in this group to prevent a misdiagnosis of dementia. The recent national dementia strategy ${ }^{3}$ has also placed a strong emphasis on specialist assessment and accurate diagnosis.

I agree that subjecting a frail older person in their 90 s with a clear history of insidious onset and gradually progressive memory loss to all the battery of investigations may be unwise but I feel that these investigations should remain an intrinsic part of a comprehensive assessment of someone presenting with a mild cognitive impairment in their 70s or earlier.

1 Foy K, Okpalugo C, Leonard F. Usefulness of routine blood tests in dementia work-up [letter]. Psychiatr Bull 2009; 33: 481.

2 Hejl A, Høgh P, Waldemar G. Potentially reversible conditions in 1000 consecutive memory clinic patients. J Neurol Neurosurg Psychiatry 2002; 73: 390-4.

3 Department of Health. Living Well with Dementia: A National Dementia Strategy. Department of Health, 2009.

Balamurugan Ganesan is ST6 in Old Age Psychiatry, Erewash Older Adults CMHT Ilkeston Resource Centre, Derbyshire. Email: balamurgan. ganesan@derbysmhservices.nhs.uk

doi: $10.1192 / p b .34 .2 .73 a$

\section{CORRECTIONS}

Get Through Workplace Based Assessments in Psychiatry (2nd edn) (review). Psychiatric Bulletin 2009; 33: 358. The author of this book is Sree Prathap Mohana Murthy. The publishers apologise to both the author and to Dr Oakley for this error, which has been corrected in the online version in deviation from print and in accordance with this correction.

Review needs re-review (letter). Psychiatric Bulletin 2009; 33: 483. This letter was published in error: the mistake described was the publishers' own. The publishers apologise for any embarrassment caused to Dr Oakley.

The Psychiatrist cover image, vol. 34 issue 1: the following notice should have been printed: (iStockphoto.com/Steve Cady. Used for illustrative purposes only; the person depicted is a model. The online journal has been corrected post-publication, in deviation from print and in accordance with this notice. doi: $10.1192 / p b .34 .2 .74$

\section{Obituaries}

\section{Dr Ruth Seifert}

\section{Formerly Consultant Psychiatrist at St Bartholomew's} and Hackney Hospitals

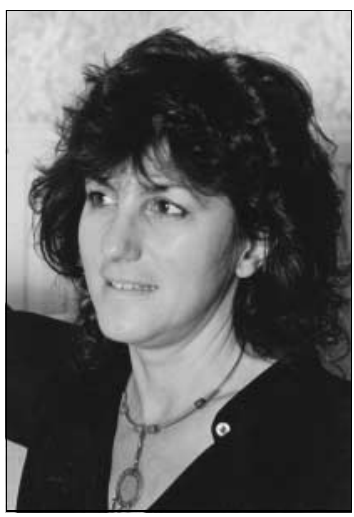

Ruth was born in North London on 20 December 1943, into a large, radical Jewish family. Her father, Sigmund, was a wellknown left-wing lawyer, and her mother, Connie, a political activist. Reportedly very noisy and hospitable, the Seifert household produced four energetic siblings, Ruth's three brothers excelling in law and academe, and her sister becoming a leading head teacher.

Ruth attended Camden School for Girls and then went to Guy's Hospital Medical School, marrying Charles Clarke, a neurologist (and Everest mountaineer), in 1971. At the time, she was a senior house officer in psychiatry at Guy's, but moved on to the Maudsley \& Bethlem Royal Joint Hospital in 1973, where she completed her postgraduate training. A major influence at the Maudsley was Dr Denis Leigh, a wise and practical physician/psychiatrist of the old school, who wore a white coat and enjoined comprehensive clinical management and a personalised approach to managing chronic neuroses.

Ruth's stay at the Maudsley was prolonged by having her first daughter Rebecca in 1973 and her second, Naomi, in 1976. Their presence in the hospital canteen, with Ruth (as often as not Gauloise in mouth) declaiming loudly, was one of the joys of training there in the 1970s. Moving to Barts and Hackney (the in-patient psychiatric unit was based at the latter) in 1980, after initially working as a locum, Ruth took on one of the most demanding clinical posts in London.

Until her retirement in 1998, taken early because of her despair at the repetitive changes of NHS management, Ruth worked often single-handedly to provide a proper service. Hackney Hospital, with its five acute wards stacked up in 'F Block', was a Victorian infirmary workhouse, decried as a 'rat-pit', intermittently affected by clostridial infections, and sitting on a network of tunnels and outbuildings in which patients would get lost. Never designed as a psychiatric 